\title{
Vairimorpha (Nosema) ceranae (Opisthosporidia: Microsporidia) in vitro Infection of Sf9 Insect Cell Line as an Experimental Model of Parasite - Host Interrelations
}

Igor Senderskiy*, Anastasiya Ignatieva, and Viacheslav Dolgikh

${ }^{1}$ All-Russian Institute of Plant Protection, Podbelskogo 3, 196608, St. Petersburg, Pushkin, Russia

\begin{abstract}
Microsporidia Vairimorpha (Nosema) ceranae is an emergent parasite of honeybee Apis mellifera and has a great concern to apiculture due to high pathogenesity and fumagillin resistance. Recently RNA interference and single-chain antibodies technologies are proposed to create unsusceptible to intracellular parasites breeds of insects. In this study we established cell culture model system to provide a way to investigate the molecular basis of interactions between honeybee and its pathogen. As the first step in this direction $V$. ceranae spores were isolated from living bees, properly sterilized and in vitro germinated with Sf9 lepidopteran-derived cell line. The entire life circle of this parasite was achieved. This should allow us to develop the novel treatment strategy directed to inhibit propagation of $V$. ceranae intracellular stages with recombinant antibodies targeted to the vitally important membrane transporters.
\end{abstract}

\section{Introduction}

Vairimorpha (Nosema) ceranae and Vairimorpha (Nosema) apis are obligate intracellular parasites of honeybee Apis mellifera midgut epithelium. But this is $V$. ceranae which is considered as a one of the reasons of the colony collapse disorder which leads to decline in pollinator populations in natural and agricultural ecosystems. $V$. ceranae as an emergent parasite of $A$. mellifera has greater pathogenic effect than $V$. apis, is more prevalent and produces higher spore loads per bee [1]. V. ceranae appeared to be resistant to fumagillin the only drug approved for microsporidiosis (nosemosis) control in honeybees several decades ago [2].

While the search for new effective chemicals active against $V$. ceranae is being continued [3], alternative approaches to suppress microsporidia intracellular development have also been suggested. Those are based on RNA interference [4-6] and single-chain antibodies (scFvs) [7]. The latter technology was successfully applied to decrease the mosquito Anopheles stephensi infection levels using scFvs against two surface proteins of apicomplexan parasite Plasmodium falciparum [8]. It has also been demonstrated that scFvs

\footnotetext{
* Corresponding author: senderskiy@mail.ru
} 
targeted to $N$. bombycis spore wall protein 12 can inhibit proliferation of this parasite in vitro [7].

As a typical microridia pathogen, $V$. ceranae largely relies upon host cell metabolic system by "stealing" its substrates with the help of membrane ATP translocases and hexose transporters [9]. There is therefore an opportunity to use scFvs raised against these proteins in order to inhibit their functional activity and prevent the proliferation of parasite. We suppose such an approach to be promisiing for protection of honeybees from nosemosis.

To develop such an approach an appropriate experimental model system is required to investigate molecular mechanisms of parasite-host interrelations. In this research we performed in vitro infection of Sf9 cell line with $V$. ceranae spores. This cell line is derived from pupal ovarian tissue of fall armyworm Spodoptera frugiperda (Lepidoptera: Noctuidae). There are no available permanent bee or other hymenoptera cell cultures so the heterologous lepidopteran-derived cells are used. Lepidopteran insects have been shown to be susceptible to $V$. ceranae under natural conditions [10]. Moreover, Sf9 cell line was proved to be susceptible to $V$. ceranae in vitro [11].

\section{Materials and Methods}

Spores of the parasite were isolated from artificially infected live A. mellifera. After midgut dissection and homogenization in distilled water as it was previously described [11] spores were additionally purified on $50 \%$ Percoll gradient to separate them from pollen and dense insect tissue. Prior to cell line infection, spores were sterilized with antiseptic Multicide (Sante-Farm, Russia) for 30 min followed by washing in sterile water. Then the spores were desiccated in a well of 6-well plate for 30 min under laminar flow. Germination of spores began immediately after rehydratation in cultural medium with insect cell suspension and polar tube extrusion was observed during 1 hour. Infected cells were cultivated at $27^{\circ} \mathrm{C}$ with presence of streptomycin and amphotericin B. Cells were separated from the spores using 20 $\%$ Percoll gradient on the next day post infection. Visualization of $V$. ceranae intracellular stages was carried out with 4',6-diamidino-2-phenylindole (DAPI) fluorescent dye and immunofluorescence assay with antibodies raised against parasite $\beta$-tubulin.

\section{Results and Discussion}

The prevalence of infection did not exceed $10 \%$. This value was reached at an infection ratio 1 cell per 25 spores. On the $3^{\text {rd }}$ day post infection spindle-like meronts can be seen. On the 5 -th day round-shape sporonts and on the 7-th sporoblasts and first spores appeared. Ten days post infection only mature spores were observed in cells and cultural medium where they laid in compact groups in the place of destroyed host cell (Fig. 1). There was no evidence that these newly generated spores can infect other cells in the cell culture without specific germination stimuli. 

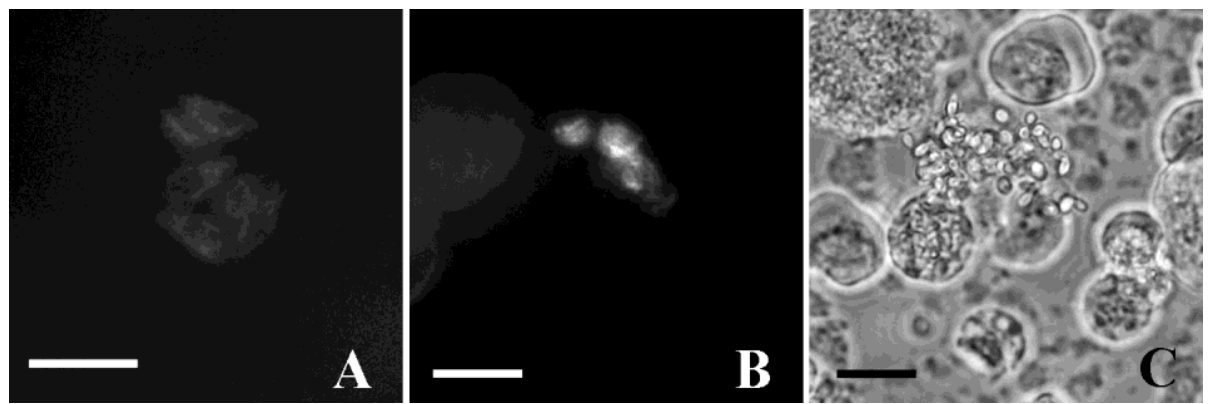

Fig. 1. Nosema ceranae life cycle stages in Sf9 cells: A - meronts, B - sporonts, and $\mathrm{C}$ - spores released from destroyed cell. Scale bar: A, B $-10 \mu \mathrm{m}, \mathrm{C}-20 \mu \mathrm{m}$.

To improve our parasite-host experimental system we need to achieve greatly the prevalence of infection by finding out more appropriate spore germination conditions. Also in further studies we should learn to carry out continuous reproduction of $V$. ceranae in Sf9 culture regularly introducing uninfected cells instead of destroyed by parasite ones. The latter will make it possible to constantly reproduce the infectious material that is needed for studying the molecular basis of parasite-host relationships of microsporidia and insects in vitro. Also it is indispensible for infecting of insect cell cultures transformed with genes of recombinant single-chain antibodies to ATP/ADP carriers and hexose transporters of $N$. ceranae to assess their resistance to these parasite.

The research was supported by Russian Science Foundation, grant \# 18-16-00054

\section{References}

1. M. Higes, P. Garcia-Palencia, R. Martin-Hernandez, A. Meana, J. Invertebr. Pathol. 94(3), 211-217 (2007)

2. W.F. Huang, L.F. Solter, P.M. Yau, B.S. Imai, PLoS Pathog., 9, e1003185 (2013)

3. S. Gisder, E. Genersch, PLoS ONE. http://doi.org/10.1371/journal.pone.0117200 (2015)

4. N. Paldi, E. Glick, M. Oliva, Y. Zilberberg, L. Aubin, J. Pettis, Y. Chen, and J.D. Evans, Appl. Environ. Microbiol. 76, 5960-5964 (2010)

5. C. Rodríguez-García, J.D. Evans, W. Li, B. Branchiccela, J.H. Li, M.C. Heerman, O. Banmeke, Y. Zhao, M. Hamilton, M. Higes, R.Martín-Hernández, Y.P. Chen, J. Exp. Biol. 221, jeb184606 (2018)

6. Q. Huang, Y. Chen, P. Neumann, J. D. Evans, Fungal Genomics Biol. 6, 1-4 (2016).

7. Y. Huang, J. Chen, B. Sun, R. Zheng, B. Li, Z. Li, Y. Tan, J. Wei1, G. Pan, C. Li, Z. Zhou, PLoS ONE. https://doi.org/10.1371/journal.pone.0193065 (2018)

8. A. T. Isaacs, F. Li, N. Jasinskiene, X. Chen, X. Nirmala, O. Marinotti, J.M. Vinetz, A.A. James, PLoS Pathog. 7(4), e1002017 (2011)

9. B.A.P. Williams, V.V. Dolgikh, Y.Y. Sokolova, Microsporidia: pathogens of opportunity (Wiley-Blackwell, 2014)

10. J.M. Malysh, A.N. Ignatieva, K.S. Artokhin, A.N. Frolov, Y.S. Tokarev, Parasitol.

Res. 117(9), 3039-3044 (2018) http://doi.org/10.1007/s00436-018-5987-3

11. E. Genersch, S. Gisder, K. Hedtke, W.B. Hunter, N. Möckel, U. Müller, J. Apic. Res. 52(1), 1-8 (2013) 